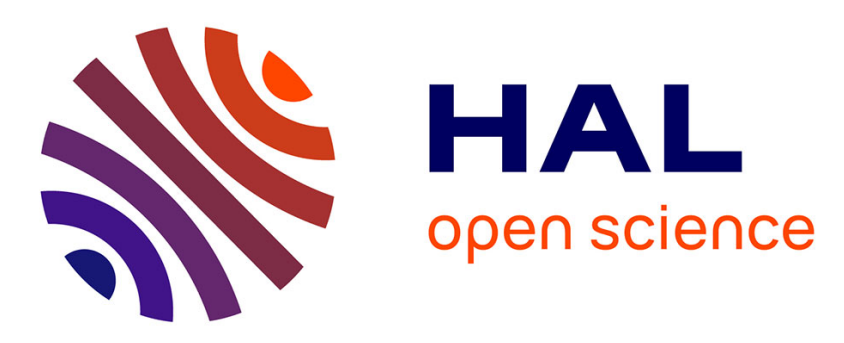

\title{
An inductorless CMOS UWB pulse generator with active pulse shaping circuit
}

\author{
Sylvain Bourdel, R. Vauche, O. Ramos, E. Muhr, Jean Gaubert, N. Dehaese,
} Herve Barthelemy

\section{- To cite this version:}

Sylvain Bourdel, R. Vauche, O. Ramos, E. Muhr, Jean Gaubert, et al.. An inductorless CMOS UWB pulse generator with active pulse shaping circuit. 2013 IEEE International Conference on UltraWideband (ICUWB), Sep 2013, Sydney, Australia. 10.1109/ICUWB.2013.6663843 . hal-01856909

\section{HAL Id: hal-01856909 \\ https://hal.science/hal-01856909}

Submitted on 20 Dec 2021

HAL is a multi-disciplinary open access archive for the deposit and dissemination of scientific research documents, whether they are published or not. The documents may come from teaching and research institutions in France or abroad, or from public or private research centers.
L'archive ouverte pluridisciplinaire HAL, est destinée au dépôt et à la diffusion de documents scientifiques de niveau recherche, publiés ou non, émanant des établissements d'enseignement et de recherche français ou étrangers, des laboratoires publics ou privés. 


\title{
An Inductorless CMOS UWB Pulse Generator with Active Pulse Shaping Circuit
}

\author{
S. Bourdel ${ }^{1}$, R. Vauché ${ }^{2}$, O. Ramos ${ }^{1}$, E. Muhr ${ }^{1}$, J. Gaubert ${ }^{1}$, N. Dehaese ${ }^{1}$, H. Barthelemy ${ }^{3}$, \\ ${ }^{1}$ Aix-Marseille University, ${ }^{2}$ ISEN-Toulon, ${ }^{3}$ Toulon University, IM2NP, and CNRS \\ Campus de Saint-Jérôme, Case 142 \\ Avenue Escadrille Normandie Niemen \\ F-13397 Marseille, France
}

\begin{abstract}
The design of an UWB pulse generator is presented. The pulse generator is based on an elementary pulse combination technique which enables the emitted pulse to be precisely shaped. This technique is implemented with no inductor or passive network and can be used to ensure regulation compliance. This generator has been fully integrated in a $0.13 \mu \mathrm{m}$ CMOS standard technology. Its area is $0.06 \mathrm{~mm}^{2}$ only and it can be programmed to synthesize different pulse shapes. For FCC compliant pulse shapes, the maximum measured $10 \mathrm{~dB}$ bandwidth is $3.5 \mathrm{GHz}$, and the maximum peak to peak magnitude is $220 \mathrm{mV}$. The measured maximal power consumption is $87.6 \mathrm{~mW}$ at $800 \mathrm{MHz}$ Pulse Repetition Frequency (PRF).
\end{abstract}

Pulse Generator, UWB, FCC, CMOS, Impulse Radio, Pulse Shaping.

\section{INTRODUCTION}

Interest has grown for Ultra Wide Band (UWB) Impulse Radio (IR) applied to low cost communication systems since it was proposed as a possible physical layer for the IEEE 802.15.4 standard. Recent works show the potential of IR for power saving thanks to the low energy of the emitted pulse and also for multipath resistance, due to the use of energy detectors in low cost receivers [1]. Since of those advantages, IR is also well suited to other low cost applications such as Body Area Network (BAN) [2], Radio Frequency IDentification (RFID) [3] and Sensor NetWork (SNW).

Currently, most pulse generator topologies for UWB-IR require inductors or a passive pulse shape networks to operate which is a major drawback for CMOS integration and production cost. Typically, the LO switching technique uses LC topologies [6] and the filter excitation technique needs a passive resonator [4] for their implementation. To limit the use of inductors, architectures based on ring oscillators or based on digital pulse shaping have been proposed [5][9][10][7]. However, according to recent publications, those techniques still use passive components (filters, baluns or matching cells) that shape the pulse in order to comply with regulation spectrum masks. To reduce the need for such passive networks, a solution is to design pulse generators with active pulse shaping circuits. Active pulse shaping techniques enable a better control of the output spectrum. It can especially be used to reduce the side lobes of the output spectrum which limit the Adjacent Chanel Power Ration (ACPR) in the case of multi-band communications. For example, a side-lobe rejection of $20 \mathrm{~dB}$ is needed to comply with IEEE $802.15 .4 \mathrm{a}$ standard. Among the different pulse shaping techniques already presented [12], only a few of them enable the reconfiguration of the shape. The elementary pulse combination technique appears to be well suited to the design of pulse synthesizers with pulse shape tuning capabilities [8] [9] [11].

In this paper, we present a practical implementation in a $0.13 \mu \mathrm{m}$ CMOS technology of a technique described in [8]. Some measurement results of different pulse shapes are also presented to validate the efficiency of the tuning capability of the proposed pulse generator. The first section of this paper presents the principle of pulse synthesis used in the proposed pulse generator. The circuit design is detailed in the second section and the measurement results are given in the last part.

\section{Pulse Synthesis PRINCIPLE}

The pulse synthesis technique consists in combining elementary baseband pulses $\left(e_{n}(t)\right)$ in order to generate a more complex signal. A bandpass pulse $(p(t))$ can be expressed as follows :

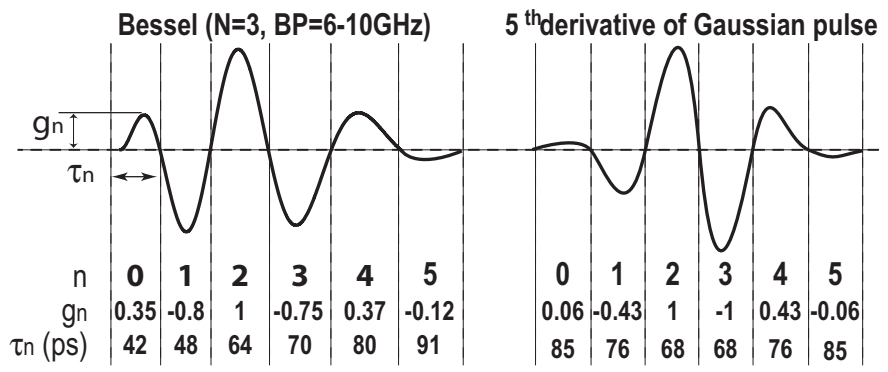

a)

b)

Fig. 1. Bessel impulse response (a) and $5^{\text {th }}$ Gaussian pulse (b) with their associated parameters $\left(g_{n}\right.$ and $\left.t_{n}\right)$ for pulse synthesis. 


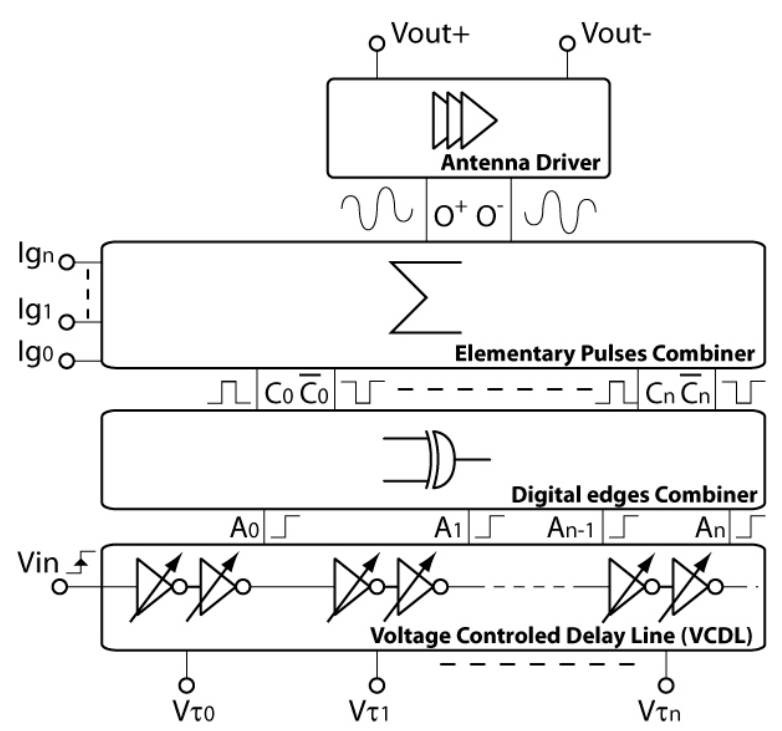

Fig. 2. Principle of the presented pulse generator

$$
p(t)=\sum_{n=0}^{N-1} g_{n} \cdot e_{n}\left(t-\sum_{p=-1}^{n-1} \tau_{p}\right) \text { with } \tau_{-1}=0
$$

where $g_{n}$ and $\tau_{n}$ refer to the magnitude and the width of the $\mathrm{n}^{\text {th }}$ elementary pulse $\left(e_{n}(t)\right)$. In Fig. 1 two different bandpass pulses are plotted with their associated coefficients $\left(g_{n}\right.$ and $\left.\tau_{n}\right)$ : the $5^{\text {th }}$ derivative of a Gaussian pulse (named $5^{\text {th }}$ Gaussian pulse in this paper) and the impulse response of $3^{\text {rd }}$ order Bessel filter (named Bessel pulse in this paper). The $5^{\text {th }}$ Gaussian pulse is known to be FCC compliant [13] and the Bessel pulse presented here has a $4 \mathrm{GHz}$ bandwidth centered at 8GHz. Moreover, $p(t)$ spectrum is slightly dependant on $e_{n}(t)$ shape. This enables FCC compliant pulses to be synthesized with the same elementary pulse $(e(t))$ having the same width $\tau$ [11] which reduces the system complexity.

\section{UWB PULSE SYNTHESIZER DESIGN}

The principle of the synthesizer is given in Fig. 2. It consists of a Voltage Controlled Delay Line (VCDL) that propagates a rising edge. Two consecutive edges $\left(A_{n-1}\right.$ and $A_{n}$ in Fig. 2$)$ are then combined to produce complementary elementary baseband pulses ( $C_{n}$ and $\overline{C_{n}}$ in Fig.2). Varying delay cells are used in the VCDL to control the width $\left(\tau_{n}\right)$ of the elementary
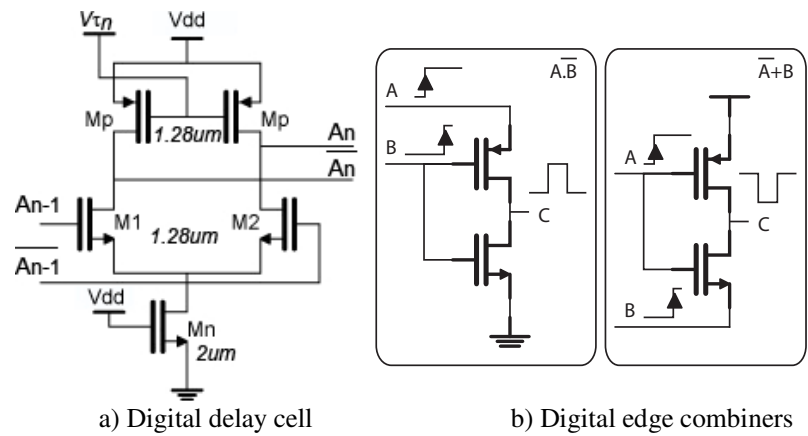

b) Digital edge combiners

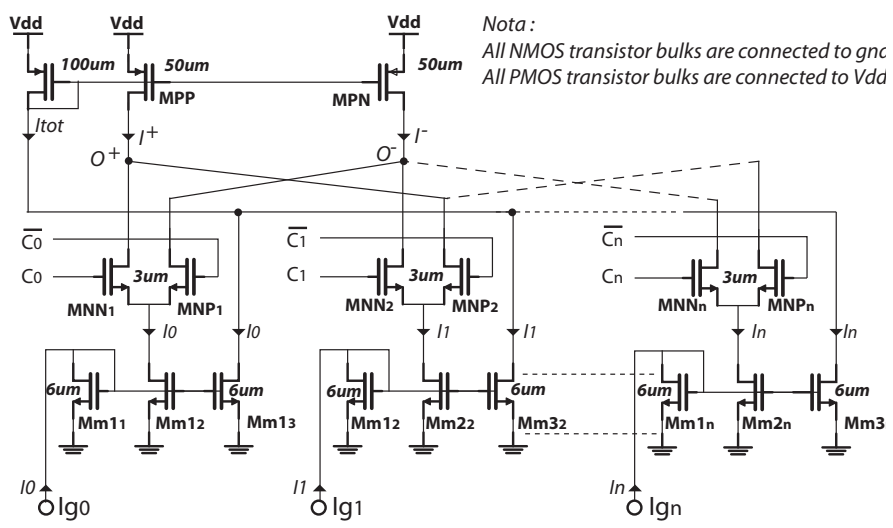

Fig. 4. Elementary pulse combiner

pulses. Complementary pulses are needed here because differential pairs in the elementary pulse combiner are used. Once the elementary pulses are combined, the resulting bandpass pulse is applied to a $50 \Omega$ antenna using a driver. The antenna is driven in a differential mode in order to maximize the output power.

The delay cells are MOS Current Mode Logic inverters [4] shown in Fig.3a, and provide very low delay. An external bias voltage is applied at node $V \tau_{n}$ to control the width of the elementary pulses $\left(\tau_{n}\right)$. Varying this bias voltage modifies the dynamic resistance of the transistors $\mathrm{Mp}$ which in turn changes the delay of the cell. The logic gates that make the edge combination are fast logic gates and use only two transistors as shown in Fig. $3 b$. Those fast logic gates are connected to the output nodes of the delay cells and achieve $A_{n-1} \cdot \overline{A_{n}}$ and $\overline{A_{n-1}}+A_{n}$ functions. Dummy cells are also connected to nodes $\overline{A_{n}}$ in order to avoid mismatch because only $A_{n}$ is used by the logic gates. Inverters are added between the delay cells and the edge combiner to reduce the rising time of the output delay cell signal.

The elementary pulse combiner is based on traditional twotransistor differential pairs $\left(M N N_{n}\right.$ and $\left.M N P_{n}\right)$ as shown in Fig. 4. Each baseband pulse and its opposite $\left(C_{n}\right.$ and $\left.\overline{C_{n}}\right)$ are applied to the differential input of the pair to produce a differential impulse current through the output nodes $O^{+}$and $O^{-}$. The combination of each elementary pulse is achieved at node $O^{+}$and $O^{-}$. The crossing of each pair output with the following one alternates the polarity of two successive elementary pulses which is necessary to synthesize the pulse

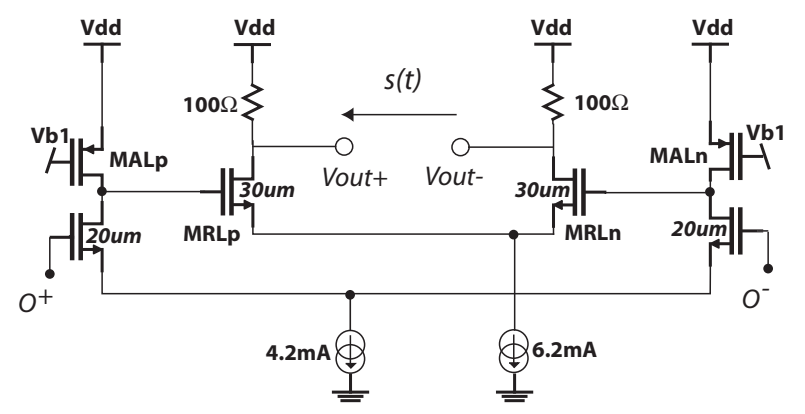

Fig. 5. Antenna driver

Fig. 3. Logic cells of the synthesizer 


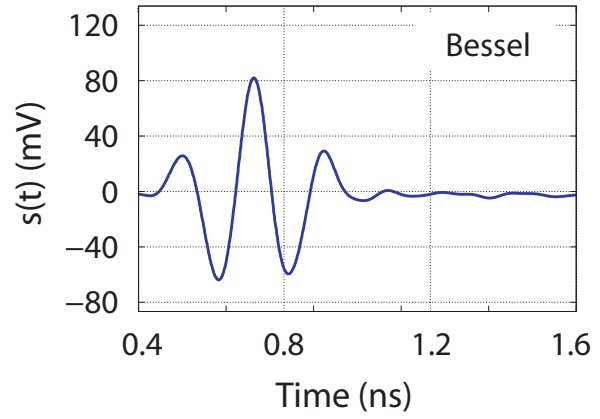

a)

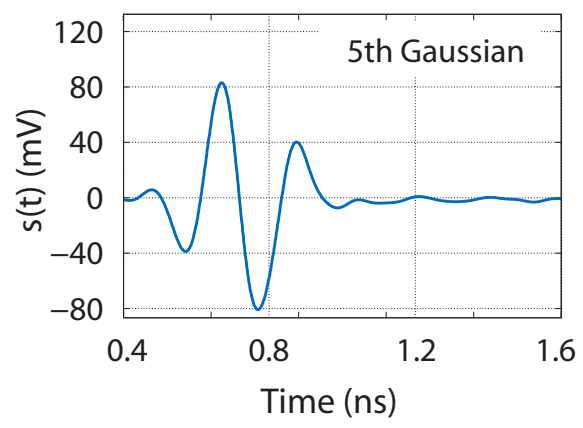

b)

Fig. 6. Measured time response of the differential output $(\mathrm{s}(\mathrm{t}))$ for a Bessel pulse synthesis (a) and a $5^{\text {th }}$ Gaussian pulse synthesis (b)

shown on Fig. 1. External bias currents $I_{0}$ to $I_{n}$ are applied at nodes $I g_{0}$ to $I g_{n}$ in order to control the elementary pulse magnitude $\left(g_{n}\right)$. Varying $I_{n}$ changes the gain of the differential pair which modifies $g_{n}$. To maintain a constant bias voltage at the nodes $O+$ and $O$ - when $I_{n}$ vary, two active loads (MPP and $M P N)$ are used. $M P P$ and $M P N$ are biased by $I_{\text {tot }}$ which is the sum of all the bias currents $\left(I_{n}\right)$ obtained by current copy with $M m 1_{n}, M m 2_{n}$ and $M m 3_{n}$.

The antenna driver is presented in Fig. 5 and consists of a common source amplifier with a resistive load driven by a common source stage with an active load. Both stages operate in A class. The output stage is designed in order to drive a simple dipole antenna in differential mode. Thus, the $100 \Omega$ output loads leads to a $50 \Omega$ differential impedance and no coupling capacitors are used. Active loads $\left(M A L_{p}\right.$ and $\left.M A L_{\mathrm{n}}\right)$ are biased with the same current copy structure used in the elementary pulse combiner. Since this topology is sensitive to common mode effect, the driver has been intensively characterized with Monte-Carlo simulations in order to maintain the gain over a large range of PVT variation.

\section{MEASUREMENT Results}

The pulse synthesizer has been implemented in a $0.13 \mu \mathrm{m}$ CMOS technology from ST-Microelectronics. The order of the implemented synthesizer is $\mathrm{N}=7$ to generate a signal composed of seven elementary pulses. Seven external current sources connected to nodes $I g_{0}$ to $I g_{6}$ are used to control the elementary pulse magnitudes and only one voltage source $(V \tau)$ is used to set their width at the same value $\left(\tau_{n}=\tau\right)$. The use of a unique control voltage to tune the width of the elementary

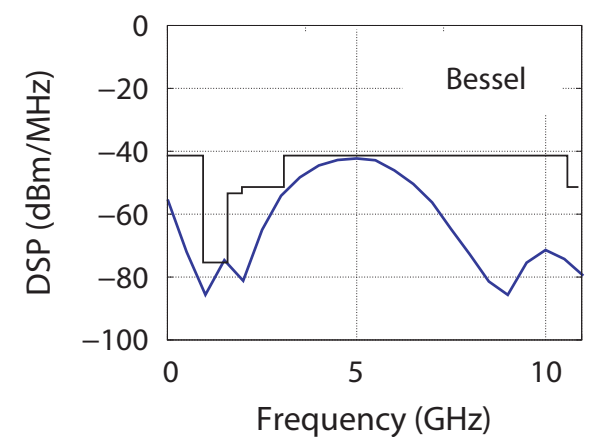

a)

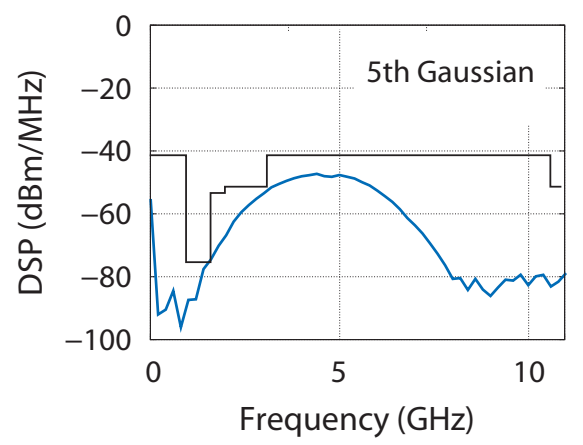

b)

Fig. 7. Measured frequency response of the differential output $(\mathrm{s}(\mathrm{t}))$ for a Bessel pulse synthesis (a) and a $5^{\text {th }}$ Gaussian pulse synthesis (b)

pulses reduces the number of I/O pads. All the presented pulses are obtained only by tuning these external sources. Measurements are performed with a two channel Agilent DSO81204B real-time oscilloscope.

The two pulses presented in Fig. 1 have been synthesized and their measured time responses are presented in Fig.6 without cable loss compensation. The values of $I_{n}$ have been slightly tuned resulting in the pulse spectrums which are compliant with FCC as represented in Fig.7. Suppressing the lower side lobes present in the output power spectrum is commonly a difficult issue which limits FCC standard compliance [12]. Using the tuning capabilities of the pulse generator, the lower side lobe has been significantly reduced as shown in the Fig. 6 and Fig. 7. The generated Bessel and $5^{\text {th }}$ Gaussian pulse exhibit a lower side lobe rejection of $30 \mathrm{~dB}$ and $38 \mathrm{~dB}$ respectively.
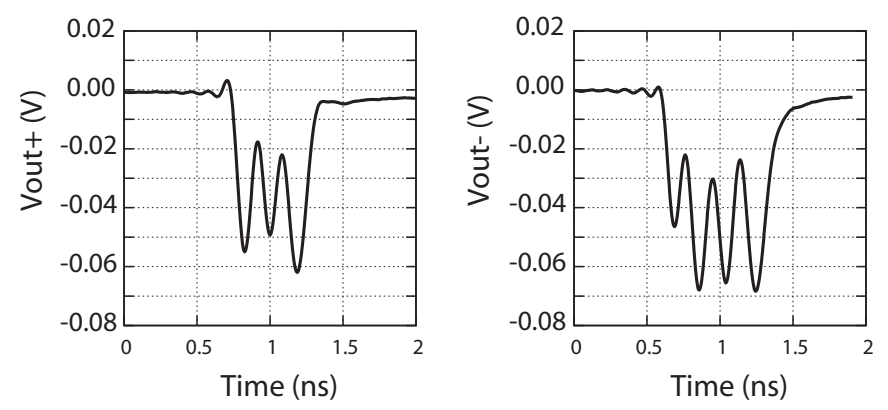

Fig. 8. Filtering effects on the outputs. 


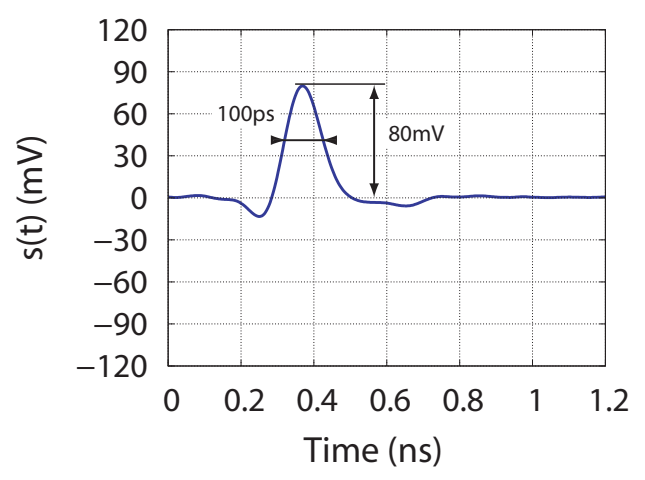

a) Elementary pulse

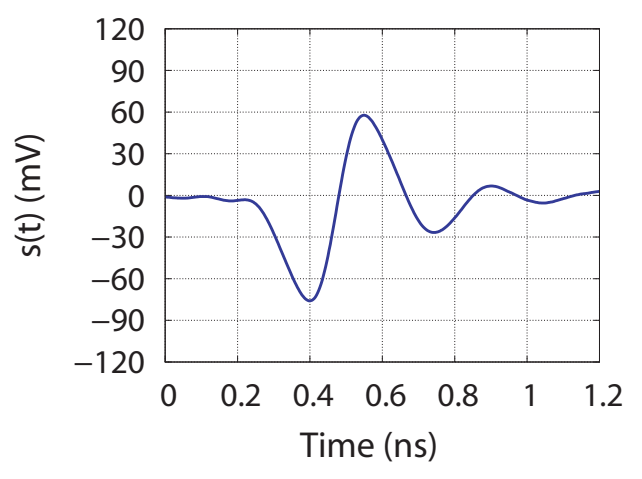

c) Combination of 3 elementary pulses

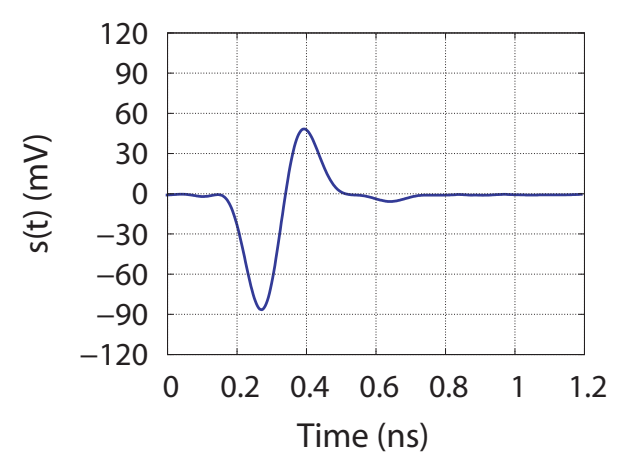

b) Monocycle pulse

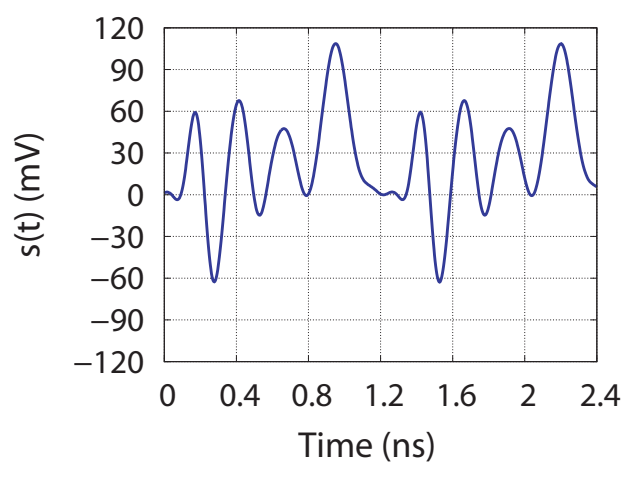

d) Arbitrary waveform at maximal PRF

Fig.9. Measurement of the tuning Capabilities

When FCC compliant pulses are synthesized, the maximum output peak to peak magnitude is $220 \mathrm{mV}$ (taking into account $3 \mathrm{~dB}$ cable loss). In this case, the maximum $10 \mathrm{~dB}$ bandwidth is $3.5 \mathrm{GHz}$ and is centered at $4.9 \mathrm{GHz}$. Compared to the theoretical pulses of Fig.1, the bandwidth is reduced. This is due to the limited bandwidth of the antenna driver and also due to the long interconnection wires between all the differential pairs (nodes $O^{+}$and $O^{-}$in Fig. 4).

As shown in Fig. 8, this filtering effect changes the pulse shape and needs to be compensated. Here, the compensation is achieved directly by tuning the values of $I_{n}$. Due to this compensation, the values of $I_{n}$ are not a linear function of $g_{n}$ and are, for the $5^{\text {th }}$ Gaussian pulse: $\mathrm{I}_{0}=0, \mathrm{I}_{1}=520 \mathrm{uA}, \mathrm{I}_{2}=1.9 \mathrm{~mA}$, $\mathrm{I}_{3}=3.1 \mathrm{~mA} \mathrm{I}_{4}=1.98 \mathrm{~mA}, \mathrm{I}_{5}=0.6 \mathrm{~mA}, \mathrm{I}_{6}=0.07 \mathrm{~mA}$. The value of $V_{\tau}$ is $0.4 \mathrm{~V}$. Such a compensation technique could also be

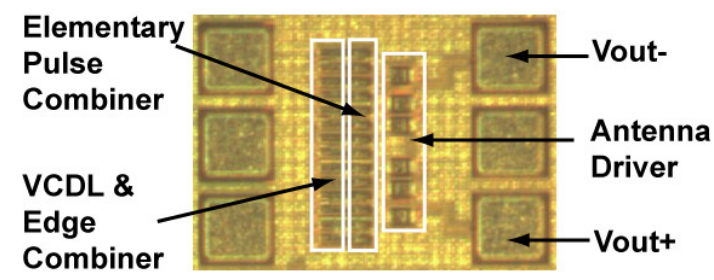

Fig. 10. Chip micro-photograph applied to cancel other effects that might change the pulse shape like PVT variations.

As presented in Fig. 9a, the measured minimum width of an elementary pulse is $100 \mathrm{ps}$. This minimum width $\left(\tau_{\min }\right)$ set to $1 /\left(2 . \tau_{\min }\right)=5 \mathrm{GHz}$ the maximal center frequency which can be achieved by the synthesizer. For such a width, the magnitude of an elementary pulse can be tuned from 0 to $80 \mathrm{mV}$. Depending on the number of elementary pulses used, the pulse generator can synthesize baseband pulses (Fig. 9a), monocyle pulses (Fig. 9b) or arbitrary waveforms (Fig. 9c and Fig. 9d).

The maximal measured Pulse Repetition Frequency (PRF) is $800 \mathrm{MHz}$ and is presented in Fig.9d using an arbitrary waveform of 7 elementary pulses. With such a high PRF, this topology is able to generate quasi-continuous waves having a time period equal to $T=N \tau$.

The measured jitter is lower than $25 \mathrm{ps}_{\mathrm{pp}}$ and could be further reduced by using a DLL instead of a simple VCDL. The total power consumption for the pulse presented in Fig.9d is $87.6 \mathrm{~mW} @ 800 \mathrm{MHz}$ and is the maximum measured power consumption. For such a PRF, the energy consumed by pulses is $110 \mathrm{pJ}$. Here more than $50 \%$ of the power is consumed by the output stage which is designed with no inductor in order to reduce the silicon area. This design strategy results in a circuit (shown in Fig. 10) having an active silicon area (excluding the pads) of $0.06 \mathrm{~mm}^{2}$ only. TABLE I shows the good performance of the generator in terms of tuning capabilities and integration. 
TABLE I : PERFORMANCE COMPARISON WITH PREVIOUSLY PUBLISHED WORKS

\begin{tabular}{|c|c|c|c|c|c|c|c|c|c|}
\hline \multirow[b]{2}{*}{ Ref. } & \multirow[b]{2}{*}{$\begin{array}{l}\text { Vpp } \\
\text { (V) }\end{array}$} & \multirow{2}{*}{$\begin{array}{l}\text { Vdd } \\
\text { (V) }\end{array}$} & \multirow[b]{2}{*}{$\begin{array}{c}\text { BW } \\
(-10 \mathrm{~dB})\end{array}$} & \multirow[b]{2}{*}{ Power Cons. } & \multicolumn{4}{|c|}{ Integration } & \multirow{2}{*}{$\begin{array}{c}\text { Pulse Shape } \\
\text { Reconfiguration }\end{array}$} \\
\hline & & & & & $\begin{array}{c}\text { Area } \\
\left(\mathrm{mm}^{2}\right)\end{array}$ & Tech. & \begin{tabular}{|l|} 
On-Chip \\
Inductors
\end{tabular} & $\begin{array}{l}\text { Off-Chip } \\
\text { Passives }\end{array}$ & \\
\hline [9] - 2007 & 1.24 & 2.2 & $1.4 \mathrm{GHz}$ & 29.7mW@36MHz & 0.4 (core) & $\begin{array}{l}0.18 \mu \mathrm{m} \\
\mathrm{CMOS}\end{array}$ & No & Yes & Yes \\
\hline [4] - 2010 & 1.42 & 1.2 & $6.8 \mathrm{GHz}$ & 3.84mW@100MHz & 0.54 (die) & $\begin{array}{l}0.13 \mu \mathrm{m} \\
\mathrm{CMOS}\end{array}$ & Yes & No & No \\
\hline [10]- 2008 & 0.22 & 1.2 & $4 \mathrm{GHz}$ & 129mW@1.8GHz & 2.83 & $\begin{array}{l}0.09 \mu \mathrm{m} \\
\mathrm{CMOS}\end{array}$ & (balun) & No & No \\
\hline [5]- 2007 & 0.65 & 1 & $550 \mathrm{MHz}$ & - & 0.08 (core) & $\begin{array}{l}0.09 \mu \mathrm{m} \\
\mathrm{CMOS}\end{array}$ & No & Yes & No \\
\hline [7] 2009 & 0.67 & 2.1 & $4.5 \mathrm{GHz}$ & 1.38mW@50MHz & 0.11 (core) & $\begin{array}{l}0.18 \mu \mathrm{m} \\
\mathrm{CMOS}\end{array}$ & Yes & No & No \\
\hline [6]- 2008 & 0.16 & 1.5 & $520 \mathrm{MHz}$ & 1.68mW@100MHz & 0.3 (core) & $\begin{array}{l}0.18 \mu \mathrm{m} \\
\mathrm{CMOS}\end{array}$ & Yes & No & No \\
\hline This Work & 0.22 & 1.2 & $3.5 \mathrm{GHz}$ & 87.6mW@800MHz & 0.06 (core) & $\begin{array}{l}0.13 \mu \mathrm{m} \\
\mathrm{CMOS}\end{array}$ & No & No & Yes \\
\hline
\end{tabular}

\section{CONCLUSION}

The design of an UWB generator based on pulse synthesis is proposed and implemented in a $0.13 \mu \mathrm{m}$ CMOS technology which is well suited for low cost applications. The pulse generator can be programmed to synthesize different pulse shapes. The tuning capabilities that are demonstrated can be used for different needs such as side lobe suppression or impairment reduction. Our pulse generator is fully integrated in a $0.13 \mu \mathrm{m}$ CMOS technology. It is designed without inductors, baluns or additional passive networks and it can synthesize FCC compliant pulses.

\section{ACKNOWLEDGEMENTS}

This work was carried out within the GRECO project which was supported by the french Agency of the National Research (ANR) and the Secured Communicating Solutions (SCS) world class cluster.

\section{REFERENCES}

[1] Fred S. Lee and Anantha P. Chandrakasan, "A $2.5 \mathrm{~nJ} / \mathrm{bit} 0.65 \mathrm{~V}$ Pulsed UWB Receiver in $90 \mathrm{~nm}$ CMOS"; Solid-State Circuits, IEEE Journal of:Volume 42, Issue 12, Dec. 2007 Page(s): 2851-2859.

[2] Ryckaert, J.and al; "Ultra-wide-band transmitter for low-power wireless body area networks: design and evaluation";;Circuits and Systems I: Regular Papers, IEEE Transactions on; vol. 52, iss. 12, Dec. 2005 Page(s):2515 - 2525

[3] Majid Baghaei-Nejad, David S. Mendoza, Zhuo Zou, Soheil adiom, Georges Gielen, Li-Rong Zheng, Hannu Tenhunen; “A Remote-Powered RFID Tag with $10 \mathrm{Mb} / \mathrm{s}$ UWB Uplink and $-18.5 \mathrm{dBm}$ Sensitivity UHF Downlink in 0.18um CMOS" ; Solid-State Circuits Conference, 2009. ISSCC 2009. Digest of Technical Papers. IEEE International; Feb. 2009 Page(s): $198-200$.

[4] S. Bourdel, Y. Bachelet, J. Gaubert, R. Vauché, O. Fourquin, N. Dehaese, and H. Barthelemy; "A 9pJ/Pulse 1.42Vpp OOK CMOS UWB Pulse Generator for the 3.1-10.6 GHz FCC Band" Microwave Theory and Techniques, IEEE Trans. on; vol. 58 , iss. 1, Jan. 2010, Pp.: $65-73$

[5] Wentzloff, D.D.; Chandrakasan, A.P.;" A 47pJ/pulse 3.1-to-5GHz AllDigital UWB Transmitter in 90nm CMOS"; Solid-State Circuits
Conference, 2007. ISSCC 2007. Digest of Technical Papers. IEEE International; 11-15 Feb. 2007 Page(s):118 - 591.

[6] Phan, A. T.; Lee, J.; Krizhanovskii, V.; Le, Q.; Han, S.-K.; Lee, S.-G.; "Energy-Efficient Low-Complexity CMOS Pulse Generator for Multiband UWB Impulse Radio"; Circuits and Systems I, IEEE Transactions on, vol. 55, iss. 11, Dec. 2008 Page(s):3552 - 3563.

[7] Sanghoon Sim; Dong-Wook Kim; Songcheol Hong; "A CMOS UWB Pulse Generator for 6-10 GHz Applications" Microwave and Wireless Components Letters, IEEE; vol. 19, iss. 2, Feb. 2009, Page(s):83 - 85.

[8] S. Bourdel, Y. Bachelet, J. Gaubert, M. Battista, M. Egels, N. Dehaese, "Low-Cost CMOS Pulse Generator for UWB Systems," Electronic Letters, vol. 43, issue 25, pp. 1425-1427, 6 December 2007.

[9] Norimatsu, T.; Fujiwara, R.; Kokubo, M.; Miyazaki, M.; Maeki, A.; Ogata, Y.; Kobayashi, S.; Koshizuka, N.; Sakamura, K.;" A UWB-IR Transmitter With Digitally Controlled Pulse Generator"; Solid-State Circuits, IEEE Journal of; vol. 42, iss. 6, June 2007 Pp.:1300 - 1309

[10] Demirkan, M.; Spencer, R.R.; "A 1.8Gpulses/s UWB Transmitter in 90nm CMOS"; IEEE International Solid-State Circuits Conference, 2008. ISSCC 2008. 3-7 Feb. 2008 Page(s):116 - 600.

[11] R. Vauché, S. Bourdel, N. Dehaese, O. Fourquin, J. Gaubert ; « Fully Tunable UWB Pulse Generator with Zero DC Power Consumption»; ICUWB 2009. IEEE International Conference on.pp. 418-422.

[12] Dokania, Rajeev K.; Wang, Xiao Y.; Dorta-Quinones, Carlos I.; Godycki, Waclaw; Tallur, Siddharth G.; Apsel, Alyssa B.;"A $6 \mu \mathrm{W}$, $100 \mathrm{Kbps}, 3-5 \mathrm{GHz}$, UWB impulse radio transmitter"; Low-Power Electronics and Design (ISLPED), 2010 ACM/IEEE International Symposium on ; 2010 , Page(s): 91 - 94

[13] H. Kim, D. Park, Y. Joo, "All-digital low-power CMOS pulse generator for UWB system", Electronics Letters, vol. 40, no. 24, 2004, pp. 15341535 . 